\title{
Assessing the deprivation gap in stillbirths and neonatal deaths by cause of death: a national population-based study
}

Kate E Best ${ }^{1}$, Sarah E Seaton ${ }^{2}$, Elizabeth S Draper ${ }^{2}$, David J Field ${ }^{2}$, Jennifer J Kurinczuk ${ }^{3}$, Bradley N Manktelow $^{2}$, Lucy K Smith ${ }^{2}$

1 Institute of Health \& Society, Newcastle University, Newcastle upon Tyne, UK

2 Department of Health Sciences, University of Leicester, Leicester, UK

3 The National Perinatal Epidemiology Unit, Nuffield Department of Population Health, University of Oxford, UK

*Corresponding Author:

Dr Lucy Smith

Address: The Infant Mortality and Morbidity Studies (TIMMS), Department of Health Sciences, College of Medicine, Biological Sciences and Psychology, University of Leicester, Centre for Medicine, University Road, Leicester, LE1 7RH, UK

Tel: 01162525418

Fax: 01162523200

Email: lucy.smith@leicester.ac.uk

Word count: 3,106

Abstract: 235

References: 47

Short title: Socioeconomic inequalities in stillbirths and neonatal deaths 


\begin{abstract}
Objective: To investigate socioeconomic inequalities in cause-specific stillbirth and neonatal mortality to identify key areas of focus for future intervention strategies to achieve Government ambitions to reduce mortality rates.
\end{abstract}

Design: Retrospective cohort study

Setting: England, Wales, Scotland and the UK Crown Dependencies

Participants: All singleton births between 01/01/2014 and 31/12/2015 at $\geq 24$ weeks gestation

Main outcome measure: Cause-specific stillbirth or neonatal death (0-27 days after birth) per 10,000 births by deprivation quintile.

Results Data on 5,694 stillbirths (38.1 per 10,000 total births) and 2,368 neonatal deaths (15.9 per 10,000 live births) were obtained from MBRRACE-UK. Women from the most deprived areas were 1.68 (95\% CI: $1.56-1.81)$ times more likely to experience a stillbirth and 1.67 (95\% CI: $1.48-1.87)$ times more likely to experience a neonatal death than those from the least deprived areas, equating to an excess of 690 stillbirths and 231 neonatal deaths per year associated with deprivation. Small for gestational age (SGA) unexplained antepartum stillbirth was the greatest contributor to excess stillbirths accounting for $33 \%$ of the deprivation gap in stillbirths. Congenital anomalies accounted for the majority (59\%) of the deprivation gap in neonatal deaths, followed by preterm birth not SGA (2427 weeks, $27 \%)$.

Conclusions: Cause-specific mortality rates at a national level allow identification of key areas of focus for future intervention strategies to reduce mortality. Despite a reduction in the deprivation gap for stillbirths and neonatal deaths, public health interventions should primarily focus on socioeconomic determinants of SGA stillbirth and congenital anomalies. 


\section{Introduction}

Socioeconomic inequalities in stillbirths and neonatal deaths in the UK remain wide compared to other high income countries with universal access to healthcare(1-4). Various attempts have been made by the English Government to reduce the deprivation gap in infant mortality by 2010(5), but socioeconomic inequalities in infant mortality persisted in England and Wales(6). A renewed effort to improve outcomes universally have been announced across the UK with aims to halve rates of stillbirth and neonatal deaths by 2025 in England(7), to reduce stillbirths by $35 \%$ and neonatal deaths by $15 \%$ by 2019 in Scotland(8) and for reducing stillbirth in Wales(9). In order to achieve this target public health interventions aimed at reducing stillbirths and neonatal deaths need to target modifiable risk factors and one of the potential key areas is excess deaths associated with deprivation. Therefore it is important to understand which causes of death are the greatest contributors to socioeconomic inequalities in order to identify potential interventions to reduce the deprivation gap.

Large scale studies have rarely examined inequalities in perinatal mortality by cause of death(10). One previous study reported that unexplained antepartum stillbirth accounted for $50 \%$ of the deprivation gap in stillbirths in England during 2000-2007(11) and congenital anomalies and immaturity were shown to account for almost $80 \%$ of the deprivation gap in neonatal death during 1997-2007(12). Here we used data on stillbirth and neonatal mortality in England, Wales, Scotland and the UK Crown Dependencies for babies born between 01/01/2014-31/12/2015 to update the evidence base and identify the key causes of death that explain socioeconomic inequalities in stillbirth and neonatal mortality. 


\section{Methods}

Data about singleton births that resulted in stillbirth ( $\geq 24$ weeks gestational age) or neonatal death (death of a live born infant $\geq 24$ weeks gestation, at $0-27$ days after birth) born between $1^{\text {st }}$ January 2014 to $31^{\text {st }}$ December 2015 to mothers resident in England, Wales, Scotland and the UK Crown Dependencies were obtained from the Mothers and Babies: Reducing Risk through Audits and Confidential Enquiries throughout the UK (MBRRACE-UK). Since January 2013, MBRRACE-UK has been commissioned by the Healthcare Quality Improvement Partnership to undertake the Maternal, Newborn and Infant Clinical Outcome Review Programme (MNI-CORP). MBRRACE-UK collects, analyses and reports national UK perinatal surveillance data to stimulate and evaluate improvements in healthcare for mothers(13). MBRRACE-UK link detailed information on deaths reported to them by all UK hospitals with individual level information on all births in the UK and Crown Dependencies to give a single dataset of births for the whole UK and Crown Dependencies. Stillbirth, neonatal and post neonatal death registrations from statutory sources are used to ensure complete ascertainment of deaths. Data included gestational age at delivery, birth weight, ethnicity, infant sex, cause of death and socioeconomic deprivation. Deprivation was measured using the Children in Low-Income Families Local Measure, an area based measure of the proportion of children living in families within the UK that are either in receipt of out-of-work benefits or in receipt of tax credits with a reported income which is less than 60 per cent of national median income. This was allocated based on the mother's super output area (data zone for Scotland) of residence(14), geographical areas with a minimum population of 1000 residents and a mean population of 1500 . Births were ranked by their deprivation score and divided into quintiles with approximately equal numbers of total births from the least deprived $20 \%$ of areas (quintile 1) to the most deprived $20 \%$ of areas (quintile 5).

MBRRACE-UK uses the Cause Of Death \& Associated Conditions (CODAC) classification system (15). In the few cases where primary cause of death was not listed or unknown, associated cause of death was used. Where associated cause of death was reported as a congenital anomaly, this was used in place of the primary cause of death because congenital anomaly was determined to be the 
underlying cause of death(16). We further adapted the CODAC to include small for gestational age (SGA, based on birth weight below the UK tenth centile for gestational age(17)). Unknown cause of death in the antepartum period in an SGA baby, was recoded as 'unexplained antepartum SGA stillbirth'. Antepartum stillbirth not SGA with unknown or missing cause of death were coded as unexplained. Cause of stillbirth was therefore categorised as: congenital anomaly, intrapartum SGA, intrapartum not SGA, cord, fetal, infection, maternal, placenta, other, unexplained antepartum SGA stillbirth or unexplained. Cause of neonatal death was coded hierarchically as: congenital anomaly, SGA (subcategorised as 24-27 weeks gestation, 28-31 weeks, 32-36 weeks, $\geq 37$ weeks), extreme preterm delivery (subcategorised as 24-27 weeks, 28-31 weeks), cardio-respiratory, neurological, intrapartum, infection, fetal or other/ unexplained.

Denominator data on singleton births in England, Wales, Scotland and the UK Crown Dependencies during the time period was obtained from routine sources across the UK $(16,18)$.

Multiple births were excluded because of the increased risks of stillbirth and neonatal death(19-21) and differential access to fertility treatment may lead to a higher incidence of multiple births in less deprived areas. Terminations of pregnancy at any gestation were excluded. Northern Ireland was excluded because socioeconomic patterning in stillbirth and neonatal mortality is likely to vary compared to the rest of the UK, because termination of pregnancy is legal only when there is a serious risk to physical or mental health of the mother(22). Neonatal deaths in babies live born $<24$ weeks were excluded as there is variation in whether they are reported as a neonatal death or as an unreported late fetal loss(23), which could significantly impact on the mortality rates.

\section{Statistical analysis}

Stillbirth rates per 10,000 total births and neonatal mortality rates per 10,000 live births were calculated by deprivation quintile and cause of death. The association between deprivation quintile and stillbirth or neonatal death was explored using Poisson regression models with stillbirth/ neonatal death as the outcome and deprivation quintile as a continuous explanatory variable. From these models, mortality rate ratios (RRs) estimating the risk of stillbirth and neonatal death in the least 
compared to the most deprived quintile were estimated, which is a similar approach to the relative index of inequality(24). Models were refitted adjusted for ethnicity (White, Black, Asian, Mixed, Other, Unknown (stillbirths $n=864$, neonatal deaths $n=160$ )) and baby's sex. All models were fitted to all-cause mortality and then each specific cause of death.

The mortality rate in the least deprived quintile was multiplied by the total number of births to estimate the number of stillbirths and neonatal deaths if the rate in the least deprived quintile was applied across the whole population. The percentage increase between this expected frequency and the actual number of stillbirths and neonatal death i.e. the excess mortality percentage, was calculated. The proportion of the deprivation gap explained by each cause of death was also calculated, i.e. the proportion of the excess deaths in the whole population attributed to each cause.

Sensitivity analyses

To make a more appropriate comparison of the deprivation gap to that reported in previous studies of stillbirth (2000-2007) and neonatal death (1997-2007) in England(11, 12), a sensitivity analysis was performed restricted to births in England only, including neonatal deaths born $\geq 22$ weeks and using deciles of socioeconomic deprivation.

\section{Ethical approval}

MBRRACE-UK has s251 approval in England and Wales and PAC approval in Scotland to collect data about stillbirths and neonatal deaths and use denominator data about all births without consent. For this analysis, conducted as part of the MBRRACE-UK programme, anonymised data were used and therefore specific research ethics committee approval was not required. 


\section{Results}

\section{All-cause stillbirth and neonatal death}

There were 5,694 stillbirths among 1,492,755 total singleton births, equating to an overall mortality rate of 38.1 per 10,000 total births (Table 1). Forty-three (0.8\%) stillbirths and 16,083 (1.1\%) live births were excluded as there was inadequate information to allocate a deprivation index. The stillbirth rate increased with increasing deprivation quintile, ranging from 28.9 to 49.0 per 10,000 total births in the least and most deprived quintiles. This represented an excess mortality in the most deprived quintile of 20.1 stillbirths per 10,000 total births (Table 2). Women living in the most deprived quintile were 1.68 times more likely to experience a stillbirth compared to women living in the least deprived quintile (95\% CI: 1.56-1.81; $\mathrm{P}<0.001)$, with the risk decreasing but remaining significant after controlling for ethnicity and infant sex $(\mathrm{RR}=1.49,95 \% \mathrm{CI}: 1.38-1.61 ; \mathrm{P}<0.001)$ (Table 3). Applying the stillbirth rate corresponding to the least deprived quintile $(28.9$ per 10,000$)$ to the total number of births $(\mathrm{n}=1,476,629)$ equated to there being 4,271 expected stillbirths. Therefore, there was a $32 \%$ excess mortality percentage when compared to the 5,651 observed stillbirths, an excess of 1380 cases over the two year period (Table 2). Stillbirths were significantly more common among women of Asian (RR=1.72, 95\% CI: 1.60-1.85), Black (RR=2.18, 95\% CI: $1.98-2.40)$ and mixed ethnicity ( $\mathrm{RR}=1.15,95 \% \mathrm{CI}: 1.02-1.29)$ compared to women of White ethnicity, although after adjustment for sex and socioeconomic deprivation, the association was only significant for women of Asian ( $\mathrm{RR}=1.60,95 \% \mathrm{CI}: 1.49-1.73)$ and Black ethnicity ( $\mathrm{RR}=1.96,95 \% \mathrm{CI}: 1.77-2.16)$. The risk of stillbirth was not significantly different in females compared to males ( $R R=0.99,95 \%$ CI: 0.94-1.05).

There were 2,368 neonatal deaths among 1,487,061 live births, equating to an overall mortality of 15.9 per 10,000 live births. There were $23(1.0 \%)$ neonatal deaths and 16,060 (1.1\%) live births excluded due to missing deprivation index (Table 1). Neonatal mortality rates ranged from 12.8 in the least deprived quintile to 20.7 per 10,000 live births in the most deprived quintile, equating to an excess mortality of 7.9 per 10,000 live births (Table 2). Similar to stillbirth, women residing in the most compared to the least deprived quintile were 1.67 times more likely to have a baby experience 
neonatal death (95\% CI: 1.48-1.87; $\mathrm{p}<0.001)$. The risk attenuated slightly after controlling for ethnicity and infant $\operatorname{sex}(\mathrm{RR}=1.58,95 \% \mathrm{CI}: 1.40-1.78 ; \mathrm{p}<0.001)$. The percentage of all-cause neonatal death related to deprivation was $24 \%$, which implies 461 more neonatal deaths were observed in the two year period than there would have been if the least deprived neonatal death rate was applied to all live births. Neonatal deaths were significantly more common among babies of women of Asian $(\mathrm{RR}=1.47,95 \% \mathrm{CI}: 1.31-1.66)$ and Black ethnicity $(\mathrm{RR}=1.49,95 \% \mathrm{CI}: 1.26-1.77)$ than women of White ethnicity, although the effect sizes decreased after controlling for sex and socioeconomic deprivation $(\mathrm{RR}=1.37,95 \% \mathrm{CI}: 1.21-1.55$ and $\mathrm{RR}=1.34,95 \% \mathrm{CI}: 1.13-1.59$, respectively). Neonatal death was significantly less likely in females compared to males ( $R R=0.79,95 \%$ CI: 0.73-0.86; $\mathrm{P}<0.001)$

\section{Cause-specific stillbirth and neonatal death}

With the exception of cord causes, infection and intrapartum SGA, stillbirths attributed to all other causes of death were significantly associated with deprivation, with relative risks for the most compared to the least deprived quintiles ranging from 2.82 for maternal disorders to 1.53 for intrapartum not SGA (Table 3). For the commonest "cause" of stillbirth, unexplained antepartum SGA stillbirth (27\%), women were at almost double the risk of stillbirth if they resided in the least compared to the most deprived quintile $(\mathrm{RR}=1.95,95 \% \mathrm{CI}$ : $1.69-2.25 ; \mathrm{P}<0.001)$. The risks of women experiencing stillbirth caused by placental problems (16\% of stillbirths) or congenital anomalies $(8 \%$ of stillbirths), were 2.17 (95\% CI: 1.80-2.63; $\mathrm{P}<0.001)$ and $1.66(1.28-2.14 ; \mathrm{P}<0.001)$ times greater in the most compared to the least deprived quintiles, respectively. Unexplained antepartum SGA stillbirth accounted for $33 \%$ of the deprivation gap in stillbirths, followed by placental problems (25\%), and congenital anomalies (6.8\%). The cause of death was unexplained in $27 \%$ of stillbirths and in these cases there was a significant association with quintile of deprivation ( $R R=1.29,95 \% \mathrm{CI}$ : 1.12-1.49; $\mathrm{P}<0.001$ ) that accounted for $14 \%$ of the stillbirth deprivation gap.

The commonest cause of neonatal death was congenital anomalies (33\%) and preterm delivery at 2427 weeks (not SGA), 20\%) (Table 1). Socioeconomic deprivation was significantly associated with 
neonatal death in babies born with a congenital anomaly $(\mathrm{RR}=2.45,95 \% \mathrm{CI}$ : $2.00-3.02, \mathrm{P}<0.001)$, preterm at 24-27 weeks (not SGA) $(\mathrm{RR}=1.94,95 \% \mathrm{CI}$ : $1.50-2.51 ; \mathrm{P}<0.001)$, and SGA at term $(\mathrm{RR}=2.03,95 \%$ CI: $1.17-3.52 ; \mathrm{P}=0.01)$ (Table 3). There was no significant association between socioeconomic deprivation and neonatal death for any other cause of death. Congenital anomalies accounted for the majority of the deprivation gap for neonatal deaths (59\%), followed by babies born at 24-27 weeks gestational age that were not SGA (27\%).

\section{Sensitivity analysis}

Using deciles of socioeconomic deprivation and including neonatal deaths born $\geq 22$ weeks in England, the RR for neonatal in the most compared to the least deprived had a greater effect size $(\mathrm{RR}=1.79,95 \% \mathrm{CI}: 150-2.14, \mathrm{P}<0.001)$. For stillbirths born in England the effect size was slightly smaller $(\mathrm{RR}=1.59,95 \% \mathrm{CI}: 1.41-1.80, \mathrm{P}<0.001)$. 


\section{Discussion}

This study provides updated estimates of the deprivation gap in stillbirths and neonatal deaths in England, Wales, Scotland and the UK Crown Dependencies. Women living in the most deprived areas were $68 \%$ and $67 \%$ more likely to have a stillbirth or have a baby who died in the neonatal period compared to those living in the least deprived areas of the UK. This equated to an excess of 690 stillbirths and 231 neonatal deaths per year (24\% and $20 \%$ of deaths, respectively). Unexplained antepartum SGA stillbirth and placental problems were the greatest contributors to the stillbirth deprivation gap. Congenital anomalies and extremely preterm birth (24-27 weeks gestational age) not associated with SGA accounted for the greatest proportions of the deprivation gap in neonatal deaths.

The stillbirth rates were lower than those reported between 2000-2007 in England (38.1 versus 45.6 per 10,000 total births) and the neonatal death rates were lower than those reported between 1997 2007 in England (15.9 versus 28.9 per 10,000 live births)(11, 12); this shows rates have decreased over time, as has been reported in Europe between 2004-2010(25). However, some of this reduction is due to the exclusion of deaths $<24$ weeks gestation compared to the previous study. Compared to the previous English studies, we found the deprivation gap to have decreased for stillbirths ( $R R=2.1$ vs $1.68)$ and neonatal deaths ( $\mathrm{RR}=2.35 \mathrm{vs} 1.67)$. Although causes of death were coded using slightly different systems, we also found lower effect sizes among unexplained antepartum SGA stillbirth $(\mathrm{RR}=1.95$ vs 2.5$)$ and among neonatal deaths caused by congenital anomalies $(\mathrm{RR}=2.45$ vs 2.85$)(11$, 12). However, we excluded deaths $<24$ weeks gestation and the impact of deprivation at extremely early gestations has been shown to be high(12). Sensitivity analyses using deciles of deprivation and including neonatal deaths born at 22 and 23 weeks in England, showed our effect sizes would still have remained lower than the previous studies $(\mathrm{RR}=1.59$ and $\mathrm{RR}=1.79$ for stillbirth and neonatal death, respectively). This suggests that the deprivation gap in stillbirths and neonatal deaths has decreased in Great Britain.

A recent study reported an increased risk of neonatal mortality (defined as mortality between 2-27 days) in England versus Sweden (2003-2012), with a very similar effect size to that attributed to socioeconomic deprivation in our study $(\mathrm{HR}=1.66$ versus $\mathrm{RR}=1.67)(26)$. This study attributed $77 \%$ of 
the excess risk of neonatal mortality in England versus Sweden to differences in birthweight, gestational age, sex and congenital anomalies(26) which may be associated with increased socioeconomic inequalities in the UK.

We have shown that congenital anomalies were the biggest contributor to the deprivation gap in neonatal deaths, likely due to an increased birth prevalence of congenital anomalies in the babies of women living in more deprived areas $(27,28)$. This suggests that to reduce the deprivation gap in neonatal death, public health interventions would need to reduce the prevalence of congenital anomalies perhaps by targeting: smoking, unplanned pregnancy, maternal disorders (e.g. diabetes and hypertension) and maternal obesity, which are potential risk factors for congenital anomalies(29-32), patterned according to socioeconomic status(33-36) and are known to increase the risk of stillbirth and/ or neonatal death(31,37-39). Public health measures may therefore include smoking cessation services, improving peri-conceptional folic acid intake, folic acid food fortification and interventions to reduce obesity in women of childbearing age. Some of the socioeconomic inequalities in congenital anomaly prevalence may also relate to differences in the decision to terminate a pregnancy following prenatal diagnosis(40). While the choice to continue a pregnancy following a diagnosis of congenital anomaly should not be considered as a flawed decision, it is important to ensure all women have equal access to timely prenatal diagnosis, provision of information and counselling on risk.

Unexplained antepartum SGA stillbirth was the greatest contributor to the stillbirth deprivation gap. The mechanisms for the association between socioeconomic deprivation and unexplained antepartum stillbirth explained are complex but may be explained in part by placental dysfunction or smoking in pregnancy $(41,42)$. It is also possible that despite universal free maternity care in the UK, there may be differential access to scanning for monitoring growth in pregnancy. Public health interventions that target socioeconomic inequalities in stillbirth may include increased monitoring of SGA pregnancies to prevent SGA stillbirths via induced early delivery or caesarean section(43).

This study has several main strengths. Firstly, we used national high-quality population-based data with complete ascertainment of stillbirths and neonatal deaths. We examined the deprivation gap by 
multiple causes of death, which will better inform the development of cause-specific interventions. A further strength is that we were also able to adjust for ethnicity as a confounding factor, although this generally showed a small reduction in the effect sizes. Socioeconomic status is a complex concept which encompasses many different dimensions. We were only able to use an area based measure of deprivation based on income as we did not have access to individual level socioeconomic information. However, much of the effect of socioeconomic deprivation on stillbirths and neonatal death is likely to act via disparities in maternal smoking rates, obesity and comorbidities such as hypertension or pregestational diabetes, which are all associated with stillbirth(37) and neonatal death(31, 38, 39, 44), and are patterned according to socioeconomic deprivation(31, 45-47). An additional limitation of this study is that $26.9 \%$ of the stillbirths had unexplained cause. However, compared to a previous study of socioeconomic inequalities in stillbirth (2000-2007)(11), we had a lower proportion of unexplained stillbirth ( $27 \%$ vs $38 \%$ previously), indicating improved cause of death coding. In our study unexplained stillbirth accounted for $14 \%$ of the deprivation gap, which may be a result of lower postmortem uptake in deprived areas, although this requires further research.

The findings from this study can be used to identify key areas of focus for future intervention strategies to achieve the UK Government target to halve mortality rates by 2025 . We have found that congenital anomalies and extreme preterm birth continue to be the most common causes of death contributing to the deprivation gap in stillbirth and neonatal death. A continued focus on these major causes is required to achieve the reduction in mortality aspired to by 2025 .

\section{Acknowledgements}

The Maternal Newborn and Infant Clinical Outcome Review Programme delivered by MBRRACEUK is commissioned by the Healthcare Quality Improvement Partnership on behalf of NHS England, NHS Wales, the Health and Social Care division of the Scottish government, the Northern Ireland Department of Health, the States of Jersey, Guernsey, and the Isle of Man. We would particularly like to thanks all MBRRACE-UK Lead Reporters and other staff in NHS Trusts, Health Boards and 
Health and Social Care Trusts across the UK and those from the Crown Dependencies, whose contribution made it possible to collect the MBRRACE-UK data.

\section{Funding}

Lucy K Smith is funded by a National Institute for Health Research Career Development Fellowship. This article presents independent research funded by the National Institute for Health Research (NIHR). KEB is funded by a Newcastle University Medical Sciences Faculty Fellowship. The views expressed are those of the authors and not necessarily those of the NHS, the NIHR or the Department of Health.

\section{What is already known on this topic}

Despite national attempts to reduce inequalities in mortality, a decade ago women living in the most deprived quintile of England were at two-fold increased risk of stillbirth and over twice as likely to experience a neonatal death.

Unexplained antepartum stillbirth, congenital anomalies and extreme prematurity accounted for most of the deprivation gap in stillbirths and neonatal deaths.

\section{What this study adds}

Inequalities in stillbirth and neonatal mortality persist with women living in the most deprived areas were $68 \%$ and $67 \%$ more likely to experience a stillbirth or neonatal death

Public health and social policies aimed at addressing the deprivation gap are at least as important in improving stillbirth and neonatal mortality rates as a narrow medical focus on the quality of intrapartum care.

\section{References}

1. Judge K. Inequalities in infant mortality: patterns, trends, policy responses and emerging issues in Canada, Chile, Sweden and the United Kingdom. Health Sociology Review. 2009;18:12-24 Online. 
2. de Bernis L, Kinney MV, Stones W, et al. Stillbirths: ending preventable deaths by 2030. Lancet. 2016;387:703-16 doi: 10.1016/S0140-6736(15)00954-X [published Online.

3. Calling S, Li X, Sundquist J, Sundquist K. Socioeconomic inequalities and infant mortality of 46470 preterm infants born in Sweden between 1992 and 2006. Paediatric and Perinatal Epidemiology. 2011;25:357-65 Online.

4. Wood AM, Pasupathy D, Pell JP, Fleming M, Smith GCS. Trends in socioeconomic inequalities in risk of sudden infant death syndrome, other causes of infant mortality, and stillbirth in Scotland: population based study. BMJ. 2012;344:e1552 Online.

5. Department of Health. Tackling health inequalities: a programme for action. In: Stationery Office, ed.2003.

6. Office for National Statistics. Pregnancy and ethnic factors influencing births and infant mortality: 2013. 2017.

7. Department of health and social care. New maternity strategy to reduce the number of stillbirths. 2017.

8. Healthcare Improvement Scotland. Maternity and Children Quality Improvement Collaborative (MCQIC). 2016.

9. Maternity Network Wales. 1000 Lives O Fywydau. 2018.

10. Reinebrant HE, Leisher SH, Coory M, et al. Making stillbirths visible: a systematic review of globally reported causes of stillbirth. BJOG: An International Journal of Obstetrics \& Gynaecology. 2017; Online.

11. Seaton SE, Field DJ, Draper ES, et al. Socioeconomic inequalities in the rate of stillbirths by cause: a population-based study. BMJ open. 2012;2:e001100 Online.

12. Smith LK, Manktelow BN, Draper ES, Springett A, Field DJ. Nature of socioeconomic inequalities in neonatal mortality: population based study. BMJ. 2010;341:c6654 Online.

13. Kurinczuk JJ, Draper ES, Field DJ, et al. Experiences with maternal and perinatal death reviews in the UK - the MBRRACE-UK programme. BJOG: An International Journal of Obstetrics \& Gynaecology. 2014;121:41-6 Online.

14. Official Statistics. Personal tax credits: Children in low-income families local measure. 2014.

15. Frøen JF, Pinar H, Flenady V, et al. Causes of death and associated conditions (Codac)-a utilitarian approach to the classification of perinatal deaths. BMC pregnancy and childbirth. 2009;9:1 Online.

16. MBRRACE-UK. Perinatal Mortality Surveillance Report. 2014.

17. Norris T, Seaton SE, Manktelow BN, et al. Updated birth weight centiles for England and Wales. Archives of Disease in Childhood - Fetal and Neonatal Edition. 2017; doi:

10.1136/archdischild-2017-313452 [published Online.

18. MBRRACE-UK. Perinatal mortality surveillance report. 2015.

19. The Stillbirth Collaborative Research Network Writing G. Association Between Stillbirth and Risk Factors Known at Pregnancy Confirmation. JAMA : the journal of the American Medical Association. 2011;306:10.1001/jama.2011.1798 doi: 10.1001/jama.2011.1798 [published Online.

20. Anthony S, Jacobusse GW, Der Pal-de Bruin V, Karin M, Buitendijk S, Zeitlin J. Do differences in maternal age, parity and multiple births explain variations in fetal and neonatal mortality rates in Europe?-Results from the EURO-PERISTAT project. Paediatric and perinatal epidemiology. 2009;23:292-300 Online.

21. Smith LK, Manktelow BN, Draper ES, Boyle EM, Johnson SJ, Field DJ. Trends in the incidence and mortality of multiple births by socioeconomic deprivation and maternal age in England: population-based cohort study. BMJ open. 2014;4:e004514 Online.

22. Department of Health. Guidance for HSC professionals on termination of pregnancy in Northern Ireland. 2016.

23. Smith L, Draper ES, Manktelow BN, Pritchard C, Field DJ. Comparing regional infant death rates: the influence of preterm births $<24$ weeks of gestation. Archives of Disease in Childhood-Fetal and Neonatal Edition. 2013;98:F103-F7 Online.

24. Shaw M, Galbardes B, Lawlor D, Lynch J, Wheeler B, Davey Smith G. The Handbook of Inequality and Socioeconomic Position. Bristol, UK: Policy Press2007. 
25. Zeitlin J, Mortensen L, Cuttini M, et al. Declines in stillbirth and neonatal mortality rates in Europe between 2004 and 2010: results from the Euro-Peristat project. Journal of Epidemiology and Community Health. 2015; doi: 10.1136/jech-2015-207013 [published Online.

26. Zylbersztejn A, Gilbert R, Hjern A, Wijlaars L, Hardelid P. Child mortality in England compared with Sweden: a birth cohort study. The Lancet. 2018;391:2008-18 Online.

27. Dadvand P, Rankin J, Hodgson S, Rushton S. Socioeconomic Inequality and Congenital Anomalies: A Small-Area Analysis. Epidemiology. 2009;20:S29 doi:

10.1097/01.ede.0000362265.40079.6c [published Online.

28. Vrijheid M, Dolk H, Stone D, Abramsky L, Alberman E, Scott JES. Socioeconomic inequalities in risk of congenital anomaly. Archives of Disease in Childhood. 2000;82:349-52 Online. 29. Hackshaw A, Rodeck C, Boniface S. Maternal smoking in pregnancy and birth defects: a systematic review based on 173687 malformed cases and 11.7 million controls. Human reproduction update. 2011;17:589-604 Online.

30. Ingrid Goh Y, Bollano E, Einarson TR, Koren G. Prenatal Multivitamin Supplementation and Rates of Congenital Anomalies: A Meta-Analysis. Journal of Obstetrics and Gynaecology Canada. 2006;28:680-9 doi: https://doi.org/10.1016/S1701-2163(16)32227-7 [published Online.

31. Tennant PWG, Rankin J, Bell R. Maternal body mass index and the risk of fetal and infant death: a cohort study from the North of England. Human reproduction. 2011:der052 Online.

32. Garne E, Loane M, Dolk H, et al. Spectrum of congenital anomalies in pregnancies with pregestational diabetes. Birth Defects Research Part A: Clinical and Molecular Teratology. 2012;94:134-40 Online.

33. Newton S, Braithwaite D, Akinyemiju TF. Socio-economic status over the life course and obesity: Systematic review and meta-analysis. PloS one. 2017;12:e177151 Online.

34. Hiscock R, Bauld L, Amos A, Platt S. Smoking and socioeconomic status in England: the rise of the never smoker and the disadvantaged smoker. Journal of Public Health. 2012;34:390-6 doi: 10.1093/pubmed/fds012 [published Online.

35. Agardh E, Allebeck P, Hallqvist J, Moradi T, Sidorchuk A. Type 2 diabetes incidence and socio-economic position: a systematic review and meta-analysis. International journal of epidemiology. 2011;40:804-18 doi: 10.1093/ije/dyr029 [published Online.

36. Wellings $\mathrm{K}$, Jones $\mathrm{KG}$, Mercer $\mathrm{CH}$, et al. The prevalence of unplanned pregnancy and associated factors in Britain: findings from the third National Survey of Sexual Attitudes and Lifestyles (Natsal-3). The Lancet. 2013;382:1807-16 doi: https://doi.org/10.1016/S01406736(13)62071-1 [published Online.

37. Flenady V, Koopmans L, Middleton P, et al. Major risk factors for stillbirth in high-income countries: a systematic review and meta-analysis. The Lancet. 377:1331-40 doi: http://dx.doi.org/10.1016/S0140-6736(10)62233-7 [published Online.

38. Shah T, Sullivan K, Carter J. Sudden Infant Death Syndrome and Reported Maternal Smoking During Pregnancy. American Journal of Public Health. 2006;96:1757-9 doi: 10.2105/AJPH.2005.073213 [published Online.

39. Tennant PWG, Glinianaia SV, Bilous RW, Rankin J, Bell R. Pre-existing diabetes, maternal glycated haemoglobin, and the risks of fetal and infant death: a population-based study. Diabetologia. 2014;57:285-94 doi: 10.1007/s00125-013-3108-5 [published Online.

40. Smith LK, Budd JLS, Field DJ, Draper ES. Socioeconomic inequalities in outcome of pregnancy and neonatal mortality associated with congenital anomalies: population based study. $B M J$. 2011;343 doi: 10.1136/bmj.d4306 [published Online.

41. Parra-Saavedra M, Crovetto F, Triunfo S, et al. Placental findings in late-onset SGA births without Doppler signs of placental insufficiency. Placenta. 2013;34:1136-41 doi: 10.1016/j.placenta.2013.09.018 [published Online First: 2013/10/22].

42. Ko T-J, Tsai L-Y, Chu L-C, et al. Parental Smoking During Pregnancy and Its Association with Low Birth Weight, Small for Gestational Age, and Preterm Birth Offspring: A Birth Cohort Study. Pediatrics \& Neonatology. 2014;55:20-7 doi: https://doi.org/10.1016/j.pedneo.2013.05.005 [published Online.

43. Royal College of Obstetricians \& Gynaecologists. The Investigation and Management of the Small-for-Gestational-Age Fetus. 2014. 
44. Ananth CV, Basso O. Impact of Pregnancy-Induced Hypertension on Stillbirth and Neonatal Mortality in First and Higher Order Births: A Population-Based Study. Epidemiology (Cambridge, Mass). 2010;21:118-23 doi: 10.1097/EDE.0b013e3181c297af [published Online.

45. NHS Information Centre. Infant Feeding Survey 2010. 2012:174-5.

46. Agardh E, Allebeck P, Hallqvist J, Moradi T, Sidorchuk A. Type 2 diabetes incidence and socio-economic position: a systematic review and meta-analysis. International journal of epidemiology. 2011;40:804-18 doi: 10.1093/ije/dyr029 [published Online First: 2011/02/22].

47. Silva LM, Coolman M, Steegers EAP, et al. Low socioeconomic status is a risk factor for preeclampsia: the Generation R Study. Journal of hypertension. 2008;26:1200-8 Online. 
Table 1 Frequency of stillbirths and neonatal deaths by deprivation quintile and cause of death 2014-2015

\begin{tabular}{|c|c|c|c|c|c|c|c|}
\hline \multicolumn{8}{|c|}{ Deprivation quintile ( $1=$ least deprived, $5=$ most deprived $)$} \\
\hline Cause of death & 1 & 2 & 3 & 4 & 5 & Total & $\%$ \\
\hline Live births & 291,960 & 296,039 & 292,857 & 294,527 & 295,595 & $1,470,978$ & \\
\hline Total births & 292,807 & 297,027 & 293,961 & 295,783 & 297,051 & $1,476,629$ & \\
\hline Stillbirth (all-cause) & 847 & 988 & 1104 & 1256 & 1456 & 5,651 & 100 \\
\hline Congenital anomaly & 81 & 81 & 73 & 119 & 123 & 477 & 8.5 \\
\hline Cord & 40 & 58 & 39 & 43 & 59 & 239 & 4.2 \\
\hline Fetal & 30 & 35 & 38 & 50 & 47 & 200 & 3.5 \\
\hline Infection & 25 & 37 & 42 & 35 & 35 & 174 & 3.1 \\
\hline Intrapartum SGA & 10 & 21 & 6 & 15 & 20 & 72 & 1.3 \\
\hline Intrapartum not SGA & 46 & 34 & 46 & 50 & 64 & 240 & 4.3 \\
\hline Maternal & 20 & 33 & 47 & 64 & 62 & 226 & 4.0 \\
\hline Placenta & 119 & 142 & 179 & 195 & 267 & 902 & 16 \\
\hline Other & 8 & 11 & 13 & 14 & 22 & 68 & 1.2 \\
\hline $\begin{array}{l}\text { Unexplained } \\
\text { antepartum SGA }\end{array}$ & 218 & 242 & 300 & 358 & 417 & 1,535 & 27 \\
\hline Unexplained & 250 & 294 & 321 & 313 & 340 & 1,518 & 27 \\
\hline Neonatal deaths (all-cause) & 374 & 394 & 445 & 519 & 613 & 2345 & 100 \\
\hline Congenital anomaly & 97 & 112 & 152 & 177 & 236 & 774 & 33 \\
\hline 24-27 weeks SGA & 13 & 13 & 7 & 11 & 19 & 63 & 2.7 \\
\hline 28-31 weeks SGA & 9 & 6 & 8 & 9 & 9 & 41 & 1.8 \\
\hline 32-36 weeks SGA & 7 & 4 & 5 & 9 & 7 & 32 & 1.4 \\
\hline $37+$ weeks SGA & 14 & 17 & 21 & 24 & 29 & 105 & 4.5 \\
\hline 24-27 weeks not SGA & 71 & 77 & 87 & 104 & 136 & 475 & 20 \\
\hline 28-31 weeks not SGA & 36 & 34 & 33 & 48 & 34 & 185 & 7.9 \\
\hline Cardio-respiratory & 11 & 13 & 18 & 18 & 15 & 75 & 3.2 \\
\hline Neurological & 44 & 39 & 46 & 35 & 39 & 203 & 8.7 \\
\hline Intrapartum & 6 & 9 & 5 & 12 & 6 & 38 & 1.6 \\
\hline Infection & 14 & 17 & 10 & 14 & 18 & 73 & 3.1 \\
\hline Fetal & 8 & 7 & 10 & 10 & 10 & 45 & 1.9 \\
\hline Other/ Unknown & 44 & 46 & 43 & 48 & 55 & 236 & 10 \\
\hline
\end{tabular}

$\mathrm{SGA}=$ Small for gestation age, classed as below the tenth centile. Stillbirths, neonatal deaths and live births had missing child poverty index and were excluded. 
Table 2 Stillbirth and neonatal mortality rate by cause of death and deprivation quintile, excess mortality associated with deprivation (per 10,000 births*).

\begin{tabular}{|c|c|c|c|c|c|}
\hline \multirow[b]{2}{*}{ Cause of death } & \multicolumn{3}{|c|}{ Mortality rate per 10,000 births* } & \multirow[b]{2}{*}{$\begin{array}{c}\text { Excess } \\
\text { mortality \% }\end{array}$} & \multirow[b]{2}{*}{$\begin{array}{c}\% \text { of } \\
\text { deprivation } \\
\text { gap attributed } \\
\text { to cause }\end{array}$} \\
\hline & $\begin{array}{c}\text { Least } \\
\text { deprived } \\
\text { quintile }\end{array}$ & $\begin{array}{c}\text { Most } \\
\text { deprived } \\
\text { quintile }\end{array}$ & $\begin{array}{c}\text { Excess } \\
\text { mortality rate }\end{array}$ & & \\
\hline Stillbirth (all-causes) & 28.9 & 49.0 & 20.1 & 32 & 100 \\
\hline Congenital anomaly & 2.8 & 4.1 & 1.4 & 17 & 6.8 \\
\hline Cord & 1.4 & 2.0 & 0.6 & 18 & 3.1 \\
\hline Fetal & 1.0 & 1.6 & 0.6 & 32 & 2.8 \\
\hline Infection & 0.9 & 1.2 & 0.3 & 38 & 1.6 \\
\hline Intrapartum SGA & 0.3 & 0.7 & 0.3 & 43 & 1.7 \\
\hline Intrapartum not SGA & 1.6 & 2.2 & 0.6 & 3.5 & 2.9 \\
\hline Maternal & 0.7 & 2.1 & 1.4 & 124 & 7.0 \\
\hline Placenta & 4.1 & 9.0 & 4.9 & 50 & 25 \\
\hline Other & 0.3 & 0.7 & 0.5 & 69 & 2.3 \\
\hline $\begin{array}{l}\text { Unexplained } \\
\text { antepartum SGA }\end{array}$ & 7.4 & 14.0 & 6.6 & 40 & 33 \\
\hline Unexplained & 8.5 & 11.4 & 2.9 & 20 & 14 \\
\hline Neonatal deaths (all-causes) & 12.8 & 20.7 & 7.9 & 24 & 100 \\
\hline Congenital anomaly & 3.3 & 8.0 & 4.7 & 58 & 59 \\
\hline 24-27 weeks SGA & 0.4 & 0.6 & 0.2 & -3.8 & 2.5 \\
\hline 28-31 weeks SGA & 0.3 & 0.3 & 0.0 & -9.6 & 0.0 \\
\hline 32-36 weeks SGA & 0.2 & 0.2 & 0.0 & -9.3 & 0.0 \\
\hline $37+$ weeks SGA & 0.5 & 1.0 & 0.5 & 49 & 6.3 \\
\hline 24-27 weeks not SGA & 2.4 & 4.6 & 2.2 & 33 & 27 \\
\hline 28-31 weeks not SGA & 1.2 & 1.2 & -0.1 & 2.0 & -1.0 \\
\hline Cardio-respiratory & 0.4 & 0.5 & 0.1 & 35 & 1.6 \\
\hline Neurological & 1.5 & 1.3 & -0.2 & -8.4 & -2.4 \\
\hline Intrapartum & 0.2 & 0.2 & 0.0 & 26 & 0.0 \\
\hline Infection & 0.5 & 0.6 & 0.1 & 3.5 & 1.6 \\
\hline Fetal & 0.3 & 0.3 & 0.1 & 12 & 0.8 \\
\hline Other/ Unknown & 1.5 & 1.9 & 0.4 & 6.5 & 4.5 \\
\hline
\end{tabular}

*Stillbirth rate is per 10,000 total births, neonatal mortality rate is per 10,000 live births. SGA= Small for gestation age, classed as below the tenth centile. 
Table 3 Mortality rate ratios in the most compared to least deprived quintile of deprivation for stillbirth and neonatal death, by cause of death

\begin{tabular}{|c|c|c|c|c|}
\hline Cause of death & $\begin{array}{r}\text { Unadj } \\
\text { Mortality RR } \\
(95 \% \text { CI }) \\
\end{array}$ & P-value & $\begin{array}{r}\text { Adju } \\
\text { Mortality RR } \\
(95 \% \text { CI })\end{array}$ & P-value \\
\hline Stillbirth (all cause) & $1.68(1.56-1.81)$ & $<0.001$ & $1.49(1.38-1.61)$ & $<0.001$ \\
\hline Congenital anomaly & $1.66(1.28-2.14)$ & $<0.001$ & $1.29(0.98-1.69)$ & 0.07 \\
\hline Cord & $1.20(0.84-1.72)$ & 0.32 & $1.20(0.83-1.74)$ & 0.33 \\
\hline Fetal & $1.62(1.09-2.41)$ & 0.02 & $1.38(0.91-2.08)$ & 0.13 \\
\hline Infection & $1.22(0.80-1.86)$ & 0.36 & $1.07(0.69-1.66)$ & 0.77 \\
\hline Intrapartum SGA & $1.46(0.76-2.82)$ & 0.26 & $1.15(0.58-2.28)$ & 0.69 \\
\hline Intrapartum not SGA & $1.53(1.07-2.20)$ & 0.02 & $1.40(0.96-2.04)$ & 0.08 \\
\hline Maternal & $2.82(1.92-4.15)$ & $<0.001$ & $2.33(1.56-3.48)$ & $<0.001$ \\
\hline Placenta & $2.17(1.80-2.63)$ & $<0.001$ & $2.15(1.77-2.62)$ & $<0.001$ \\
\hline Other & $2.52(1.26-5.05)$ & 0.01 & $2.41(1.15-5.06)$ & 0.02 \\
\hline $\begin{array}{l}\text { Unexplained } \\
\text { antepartum SGA }\end{array}$ & $1.95(1.69-2.25)$ & $<0.001$ & $1.64(1.41-1.90)$ & $<0.001$ \\
\hline Unexplained & $1.29(1.12-1.49)$ & $<0.001$ & $1.16(1.00-1.34)$ & 0.06 \\
\hline Neonatal death (all cause & $1.67(1.48-1.87)$ & $<0.001$ & $1.58(1.4-1.78)$ & $<0.001$ \\
\hline 24-27 weeks SGA & $1.36(0.68-2.75)$ & 0.39 & $1.20(0.58-2.48)$ & 0.62 \\
\hline 24-27 weeks not SGA & $1.94(1.5-2.51)$ & $<0.001$ & $1.96(1.51-2.56)$ & $<0.001$ \\
\hline 28-31 weeks SGA & $1.15(0.48-2.73)$ & 0.75 & $0.96(0.39-2.35)$ & 0.92 \\
\hline 28-31 weeks not SGA & $1.11(0.74-1.66)$ & 0.63 & $1.01(0.66-1.54)$ & 0.96 \\
\hline 32-36 weeks SGA & $1.36(0.51-3.63)$ & 0.54 & $1.22(0.44-3.35)$ & 0.70 \\
\hline $37+$ weeks SGA & $2.03(1.17-3.52)$ & 0.01 & $1.76(1-3.12)$ & 0.05 \\
\hline Cardio-respiratory & $1.41(0.74-2.67)$ & 0.30 & $1.49(0.77-2.86)$ & 0.23 \\
\hline Congenital anomaly & $2.45(2.00-3.02)$ & $<0.001$ & $2.14(1.73-2.64)$ & $<0.001$ \\
\hline Fetal & $1.36(0.59-3.11)$ & 0.47 & $1.26(0.54-2.95)$ & 0.59 \\
\hline Infection & $1.14(0.59-2.18)$ & 0.70 & $1.3(0.67-2.5)$ & 0.44 \\
\hline Intrapartum & $1.16(0.47-2.86)$ & 0.74 & $1.35(0.52-3.48)$ & 0.54 \\
\hline Neurological & $0.86(0.59-1.28)$ & 0.46 & $0.92(0.61-1.37)$ & 0.67 \\
\hline Other/ Unknown & $1.22(0.85-1.75)$ & 0.29 & $1.2(0.83-1.75)$ & 0.33 \\
\hline
\end{tabular}

*Adjusted for ethnicity and infant sex SGA= Small for gestation age, classed as below the tenth centile. There were 87 less cases in the adjusted stillbirth analysis and 28 less cases in the adjusted neonatal death analysis due to missing sex data 